\title{
HRCT TEMPORAL BONE- A MANDATORY PREOPERATIVE INVESTIGATION FOR IMPROVING SURGICAL OUTCOME IN UNSAFE CSOM
}

\author{
Shweta Baviskar1, Laveena Mehta², Tushar Gori33, Sandeep Jakhere ${ }^{4}$
}

${ }_{1}^{1}$ Assistant Professor, Department of ENT, RGMC, Kalwa, Thane, Maharashtra, India.

${ }^{2}$ Registrar, Department of ENT, RGMC, Kalwa, Thane, Maharashtra, India.

${ }^{3}$ Postgraduate Student, Department of ENT, RGMC, Kalwa, Thane, Maharashtra, India.

${ }^{4}$ Associate Professor, Department of Radiology, RGMC, Kalwa, Thane, Maharashtra, India.

ABSTRACT

\section{BACKGROUND}

Chronic Suppurative Otitis Media (CSOM) is considered to be a slowly progressive destructive disease of the middle ear. It is the most commonly encountered middle ear pathology, which disrupts the normal anatomy and physiological functioning of the ear. Otoscopic evaluation is sufficient to establish the diagnosis of the disease; however, its extent can be determined only on the basis of a High Resolution Computed Tomography (HRCT) of the temporal bone. While the most common presentation of CSOM is a discharging ear. Its complications may be masked by the disease itself, thereby giving a false presentation of a limited extent. HRCT temporal bone can help quantify the extent of the disease and hence prioritise the patients who warrant an urgent management.

The aim of this study is to establish the importance of HRCT temporal bone in a patient with unsafe CSOM, even in absence of clinical suspicion of ongoing complication to improve the surgical outcome.

\section{MATERIALS AND METHODS}

This study has been conducted on 50 patients who have presented to the ENT OPD at RGMC, Kalwa.

\section{RESULTS}

Out of 50 patients who presented with complications, 20 patients (40\%) did not have any history suggestive of impending complications. The HRCT temporal bone helped in establishing the presence of these complications and allowing for prompt treatment.

\section{CONCLUSION}

It was found that presence of HRCT helps in determining lurking complications and thus helps in deciding the urgency with which tympanomastoidectomy surgery needs to be performed.

\section{KEY WORDS}

HRCT, Temporal Bone, Mastoid, Cholesteatoma.

HOW TO CITE THIS ARTICLE: Baviskar S, Mehta L, Gori T, et al. HRCT temporal bone- a mandatory preoperative investigation for improving surgical outcome in unsafe CSOM. J. Evolution Med. Dent. Sci. 2018;7(27):3112-3114, DOI: 10.14260/jemds/2018/699

\section{BACKGROUND}

Cholesteatoma as a disease is considered to be unsafe type of CSOM, because of its propensity to cause destruction of the neighbouring structures. The ear and its mastoid bone lie in close proximity to anatomically and functionally important structures, which if disturbed can cause debilitating complications. Moreover, the various crevices present in the mastoid bone are difficult to visualise using a conventional microscope. The cholesteatoma matrix itself sometimes bridges the erosions it has created in surrounding structures, thereby masking the clinical presentations of these complications. In a developing country due to the vast population patients from low socio-economic strata there is a widespread prevalence of this unsafe type of disease. It becomes prudent under such circumstances to determine which patients warrant management on a priority.

'Financial or Other Competing Interest': None

Submission 05-06-2018, Peer Review 18-06-2018,

Acceptance 20-06-2018, Published 02-07-2018.

Corresponding Author:

Dr. Shweta Baviskar,

\#1602, Tower-4,

Regency Heights, Bramhand,

Thane West, Maharashtra, India.

E-mail: shweta.katna@gmail.com

DOI: $10.14260 /$ jemds $/ 2018 / 699$

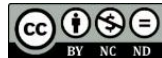

HRCT temporal bone plays an important role in this decision making. Cholesteatoma, as a disease, is diagnosed on otoscopic examination and requires a radiographic correlation.(1) The preferred method in the olden days was an $\mathrm{x}$-ray of the mastoid bone using Schuller's view. In the modern era HRCT temporal bone widely replaced the x-ray, limiting its use to determining a low lying dura or a high riding sigmoid sinus. $(1,2)$ Cholesteatoma typically presents as a soft tissue in the middle ear and mastoid cavity, causing erosion of neighbouring structures and needs to be differentiated clinically from granulation tissue.(3)

\section{Objective}

To establish the importance of HRCT Temporal Bone in a patient with unsafe CSOM, even in absence of clinical suspicion of ongoing complication to improve the surgical outcome.

\section{MATERIALS AND METHODS}

A descriptive study was conducted on 50 patients who have presented to the ENT OPD at RGMC, Kalwa. Sample size has been limited for our convenience. Every patient presented was first examined with an otoscope having a 2 Dioptre magnification. Aural toileting was done to remove any debris or co-existing discharge or otomycosis. Acetic acid ear drops were administered for a week and the ear was re-examined 
under the Carl Zeiss Microscope and further aural toileting was performed. In patients whose ears was not responding well to eardrops, washes were given on an OPD basis with $1 \mathrm{~mL}$ acetic acid diluted in $10 \mathrm{~mL}$ NS. Each patient was informed about the nature of their disease and the management required. The patients were asked to get HRCT Temporal Bone of $1.5 \mathrm{~mm}$ cuts. The patients were then assessed and posted for a mastoidectomy surgery based on the extent of disease and presence of complications.

\section{Inclusion Criteria}

- Patients with unsafe CSOM as diagnosed on Otoscopic examination and confirmed on EUM.

- $\quad$ Age Limit: 12 years to 55 years.

- Both males and females.

- Patients with complications of CSOM.

- Patients with bilateral ear disease.

- Patients giving consent for further management.

\section{Exclusion Criteria}

- Revision cases.

- Patients not giving consent for HRCT or further management.

\section{RESULTS}

A total of 50 patients who presented to the ENT Department is Rajiv Gandhi Medical College, Kalwa with Atticoantral type of CSOM were included in the study. The study has been conducted over a course of 1 year. The most commonly affected patients were within 30 - 40 years of age. 35 out of 50 patients were male and the rest were females.

\begin{tabular}{|c|c|c|}
\hline & Total & Percentage \\
\hline Males & 35 & $70 \%$ \\
\hline Females & 15 & $30 \%$ \\
\hline \multicolumn{3}{|c|}{ Table 1 } \\
\hline
\end{tabular}

Bilateral ear disease was found in 10 cases. All patients were subjected to aural toileting, pure tone audiometry and examination under microscopy. HRCT temporal bone was performed for all patients.

The soft tissue detected on the scan was found to be extensive in 25 patients.

\begin{tabular}{|c|c|c|}
\hline Location & No. of Patients & Percentage \\
\hline Attic & 5 & $10 \%$ \\
\hline Atticoantral & 10 & $20 \%$ \\
\hline Sinus tympani & 10 & $20 \%$ \\
\hline Extensive & 25 & $50 \%$ \\
\hline \multicolumn{3}{|c|}{ Table 2 } \\
\hline
\end{tabular}

Among the ossicles involved, the incus was the most commonly affected.

\begin{tabular}{|c|c|c|}
\hline Ossicle & Involved & Percentage \\
\hline Malleus & 5 & $10 \%$ \\
\hline Incus & 30 & $60 \%$ \\
\hline Stapes & 20 & $40 \%$ \\
\hline \multicolumn{3}{|c|}{ Table 3 } \\
\hline
\end{tabular}

Following features were compared between HRCT and intraoperative finding.

\begin{tabular}{|c|c|c|c|c|c|c|c|c|}
\hline 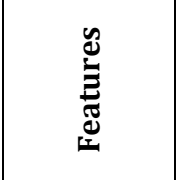 & 包: & 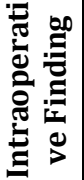 & 离 & 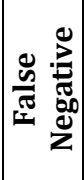 & : & 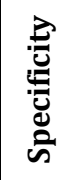 & $\vec{a}$ & $\frac{1}{z}$ \\
\hline Soft Tissue & 50 & 50 & 0 & 0 & 100 & 100 & 100 & 100 \\
\hline $\begin{array}{l}\text { Tegmen } \\
\text { erosion }\end{array}$ & 10 & 9 & 1 & 0 & 100 & 97.6 & 90 & 100 \\
\hline $\begin{array}{l}\text { Sigmoid } \\
\text { sinus } \\
\text { erosion }\end{array}$ & 15 & 20 & 0 & 5 & 80 & 100 & 100 & 87.5 \\
\hline \begin{tabular}{|c|}
$\begin{array}{c}\text { Facial canal } \\
\text { erosion }\end{array}$ \\
\end{tabular} & 10 & 14 & 0 & 4 & 77.8 & 100 & 100 & 90.9 \\
\hline \begin{tabular}{c|} 
LSCC \\
dehiscence
\end{tabular} & 3 & 2 & 1 & 0 & 100 & 97.9 & 66.7 & 100 \\
\hline \multicolumn{9}{|c|}{ Table 4} \\
\hline
\end{tabular}

Out of all patients who presented with complications, 20 patients did not have any history suggestive of impending complications. The HRCT temporal bone helped in establishing the presence of these complications and allowing for prompt treatment.

\section{DISCUSSION}

Most patients with atticoantral type of CSOM present after commencement of bony erosion. Patients present to the OPD with complaints of ear discharge. The presence of blood stained discharge should alert the examiner to the possible presence of granulation tissue or atticoantral type of CSOM. Complications of CSOM usually give rise to features of headache, giddiness, blurring of vision, facial weakness etc. $(4,5)$ HRCT shows cholesteatoma as a non-dependant soft tissue density in the middle ear with or without erosions of the ossicles and surrounding structures. When this soft tissue is present with widening of the middle ear cavity, aditus ad antrum and loss of it "figure-of-eight" appearance, it increases the likelihood of a diagnosis of cholesteatoma. ${ }^{(6-12)}$ From a surgeon's perspective, it becomes important to assess the following areas-

1. Soft tissue mass.

2. Pneumatisation of mastoid.

3. Extent of disease.

4. Tegmen tympani erosion.

5. Sinus plate erosion.

6. Facial canal dehiscence.

7. Lateral semicircular canal dehiscence.

8. Ossicular status.

9. Disease outside middle ear cleft.

The drawback of a CT scan is that it does not differentiate between granulation tissue and cholesteatoma, both of which appear as soft tissue masses. This is of particular importance in early stages of cholesteatoma, where there is a matrix of keratinising epithelium in the middle ear without the onset of bony erosion.(5-8,11) However, this does not hamper the decision making process as granulation tissue in the middle ear or mastoid cavity requires surgical removal as well. The presence of granulation tissue can lead to blockage of the aditus ad antrum, sclerosis of the mastoid bone and cause persistent ear discharge which most commonly does not respond well to oral or topical medications. 
For tegmen tympani erosion, thinner CT-scan slices on coronal sections are required. Lysis of the scutum is well visualised in frontal CT-scan images. The earliest sign of cholesteatoma is blunting of the scutum. HRCT also helps in diagnosing early erosive changes in the ossicles. The lenticular process of the incus is the first ossicle to be disrupted with loss of the "ice cream" cone appearance seen on the scan. The lateral SCC is the most frequently eroded because of its close proximity to the attic. The bony lysis of the LSCC requires the combination of coronal and axial inframillimetric slices to differentiate it from a labyrinthine fistula. The diagnosis of the fistula is made when the mass is seen in direct apposition to the lumen of labyrinth.(12-15)

One of the major drawbacks of HRCT is its inability to accurately detect small erosions of the fallopian canal due to its small size, oblique orientation in tympanic part and developmental dehiscence, particularly when abutted by soft tissue. Hence, the facial nerve canal should be evaluated in both axial and coronal scans. When a complete bony canal is present, erosion of the canal wall is easily detected on HRCT. $(9,15)$

In a developing country like India, cholesteatoma is a fairly common ENT presentation. In such scenario, understanding the extent of the disease in an individual helps in proper planning of the surgery. HRCT helps in deciding the timeframe within which the patient should be taken up for surgery. Moreover, it provides a fair preoperative warning to the surgeon about the presence of dehiscence or eroded bony structures that one may encounter during the procedure. CT also have a role to play in patients presenting with foul smelling discharge in both ears. In such cases, deciding on which ear should be operated first cannot be decided based on microscopic examination alone.

\section{CONCLUSION}

HRCT Temporal Bone is a very useful preoperative guide, which helps in deciding the management of a patient with cholesteatoma. It is also the investigation of choice in patients presenting with bilateral atticoantral type of CSOM. Due to the high cost and unavailability, not all patients undergo this scan preoperatively. HRCT should be a mandatory preoperative requirement before posting a patient for a tympanomastoidectomy surgery.

\section{REFERENCES}

[1] Som PM, Curtin HD. Text book on head and neck imaging. $4^{\text {th }}$ edn. Maryland Heights: Mosby 2003.
[2] Veillon F, Riehm S, Roedlich MN, et al. Imaging of middle ear pathology. Semin Roentgenol 2000;35(1):2-11.

[3] Maroldi R, Farina D, Palvarini L, et al. Computed tomography and magnetic resonance imaging of pathologic conditions of the middle ear. Eur J Radiol 2001;40(2):78-93.

[4] Bluestone D, Stool SE, Alper CM, et al. Pediatric Otolaryngology. $3^{\text {rd }}$ edn. Philadelphia: WB Saunders 1996.

[5] Vazquez E, Castellote A, Piqueras J, et al. Imaging of complications of acute mastoiditis in children. Radiographics 2003;23(2):359-72.

[6] Gaurano JL, Joharjy IA. Middle ear cholesteatoma: characteristic CT findings in 64 patients. Ann Saudi Med 2004;24(6):442-7.

[7] Chee NW, Tan TY. The value of pre-operative high resolution CT scans in cholesteatoma surgery. Singapore Med J 2001;42(4):155-9.

[8] Chakeres DW, Augustyn MA. Temporal Bone. In: Hagga JR, Lanzieri CF, Gilkeson RC, eds. CT and MR imaging of the whole body. $4^{\text {th }}$ edn. Mosby 2003: p. 495-552.

[9] Nemzek WR, Swartz JD. Temporal bone: Inflammatory disease. In: Som PM, Curtin HD, eds. Head and Neck imaging. $4^{\text {th }}$ edn. Mosby 2003: p. 1173-229.

[10] Zelikowich EI. Computed tomography (CT) of the temporal bone in diagnosis of acquired cholesteatoma of the middle ear. Vestn Otorhinolaryngol 2004;(5):28-32.

[11] Mafee MF, Levin BC, Applebaum EL, et al. Cholesteatoma of the middle ear and mastoid. A comparison of CT scan and operative findings. Otolaryngol Clin North Am 1988;21(2):265-93.

[12] Zylberberg F, Williams MT, Ayache D, et al. CT-scan of middle ear cholesteatoma. Feuill Radiol 2000;40:4857.

[13] Ayache D, Schmerber S, Lavieille JP, et al. Middle ear cholesteatoma. Ann Otolaryngol Chir Cervicofac 2006;123(3):120-37.

[14] Walshe P, Walsh MR, Brennan P, et al. The role of computerized tomography in the preoperative assessment of chronic suppurative otitis media. Clin Otolaryngol Allied Sci 2002;27(2):95-7.

[15] Vasdev A, Boubagra K, Lavieille JP, et al. Computed tomographic aspects of secondary cholesteatomas of the middle ear and petrous bone. J Neuroradiology 1994;21(3):181-93. 